3.I per cent. of albite. The author compares this with recorded occurrences of albite in Jurassic and other unmetamorphosed limestones, in Europe. Issel's discovery (Comptes rendus, February 24, I890) of albite crystals enclosing radiolaria in a Cainozoic limestone may be added to those quoted. Prof. Daly concludes that the alkaline felspars of Waterton crystallised out, like the European examples, at the sea-floor, or soon after the burial of the associated dolomite, and at temperatures which may have been well under $100^{\circ} \mathrm{C}$. Time, he points out, may be an important factor, and this has to be borne in mind in experimental work on such productions.

Mr. W. A. Tarr (Amer. Journ. Sci., vol. xliv., p. 409, 1917) has examined with much care the elongated chert-lumps in the Burlington Limestone of Missouri, a formation of Lower Carboniferous age. Because he finds no remains of siliceous organisms associated with the chert, and only a partial replacement of originally calcartous fossils, he criticises the view that flint is commonly a pseudomorph of portions of the limestone in which it occurs, and remarks that, had the first investigations been made on material collected in Missouri, the theory that attributes the material of flint in other cases to the solution of organic remains would not have been propounded. This shows that the author attaches little weight to the mass of evidence collected outside Missouri ; yet his reading has evidently been extensive. No reference is made to the frequent occurrence of silicified oolitic rocks, from the Assynt Limestone upwards, in which all the structure of the original limestone is retained, nor to the remarkable suggestion made by $R$. Liesegang as to the rhythmic deposition of flint layers by water holding silica in solution. Mr. Tarr does well to emphasise the fact that flint formation goes on at an early stage in the consolidation of limestone, since pebbles of the flint are often found in the next following deposits; but it does not follow from this that flint nodules represent gelatinous matter precipitated directly on the sea-floor. The shrinkage-cracks in the Missouri flint, filled by limestone, and Mr. Tarr's interesting experiments on the precipitation of silica, help towards his conclusion that the flint in the Burlington Limestone is not a replacement of the calcareous rock; but this by no means disposes of the cases where flint masses spread out into successive layers of a limestone, or of the thousands of sections from Cretaceous or Carboniferous material that are stored in European collections. We read this paper with the feeling that, if $\mathrm{Mr}$. Tarr has proved his case for the Missouri example, he has dealt with an exceptional occurrence which certainly deserved description.

It is characteristic of the association of the sciences in technical industries that geologists should be asked to look for "pulpstones." Mr. L. H. Cole has, in consequence, tested certain Canadian sandstones "to determine their suitability as pulpstones" (Canada, Dept. of Mines, Mines Branch, Bull. 19, I9I7). These are used in wood-pulp mills, and should tear the fibres apart rather than cut them. In the case of sandstones, the grains should be of medium size and medium angularity, and the stone must resist considerable stresses. Diagrams of the grinding machines add interest to this useful bulletin.

Mr. H. Ries describes a gritty plastic "clay" resembling löss (Amer. Journ. Sci., vol. xliv., p. 316 , I9I7), which proves to consist of 98.5 per cent. of small crystals of dolomite and $\mathrm{x} \cdot 5$ per cent. of iron oxide and alumina. He suggests that the flat faces of the dolomite rhombs, coming into contact or separated only by a film of water, may account for the plasticity, surface tension holding the grains together, but allowing of slipping along their faces.

NO. 253 I, VOL. IOI]
The phosphate deposits of Saldanha Bay, north-west of Cape Town, have been reported on by Dr. A. L. Du Toit (S. Africa Geol. Survey, Mem. Io, I9I 7 ). The material contains from ro to 22 per cent. of phosphoric oxide; but this is mostly combined with aluminium and iron, having been produced by the action of ancient guanos on underlying granitic rocks. The author discusses the value of such phosphates as fertilisers, making no attempt in his summary to reconcile the somewhat contradictory statements of agricultural chemists, but pointing out the need for experiments on natural lines under biochemical conditions. His proper mistrust of Germany should not have led him into the error of asserting that the citric acid test of availability of phosphorus was "devised in Germany for the purpose of enabling that country to supply the markets of the world with highly citricsoluble basic slag."

Mr. T. A. Jaggar, jun. (Journ. Washington Acad. Sci., vol. vii., p. 277 , I9I 7 ), describes the phenomena presented by the $a a$ and pahoehoe types of Hawaiian lava during the cooling of the mass. He suggests that the quantity of confined gas for each unit of volume of melt may be a controlling factor. The expansion of gas in the aa type may be more rapid, but "with so many variables there is no cause for wonder that the distinction is as yet unexplained." The author proposes the term "dermolith" for the pahoehoe type, which has a crust or skin as its chief character, and the term "aphrolith" (foam-stone) for types of lava which divide on the surface, like $a a$, into lumpy vesicular units. He prefers "lith" to "lite" as a termination, on the well-established analogy of "monolith."

Prof. R. A. Daly has furnished a useful synopsis of our knowledge of the nature of rocks in the Pacific islands (Bull. Geol. Soc. America, vol. xxvii., p. 325) and urges that much more observation is required. He believes that, so far as can be judged at present, the primary magma under the Pacific is of basaltic composition, giving rise to andesites and picrites by differentiation, and to alkaline rocks by solution of comparatively small proportions of limestone.

$$
\text { G. A. J. C. }
$$

\section{THE BIRD CULT OF EASTER ISLAND.}

IN the issue of Folk-lore for December last Mrs. Scoresby Routledge gives a singularly interesting account of the bird cult of Easter Island. The sacred bird is the sooty tern (Sterna fuliginosa), and the valued privilege of securing the first egg is a matter of competition between members of the Mata-toa group, the right to become a competitor being acquired only by supernatural agency. The selection is made through a dream vouchsafed to a divinely gifted individual, the Iviatua. The candidate on selection takes a new name, and the bird-name thus conferred was given to the year in which victory was achieved, thus forming an easily remembered system of chronology. It is also significant that this bird cult is conneoted with the statues for which the island is famous. The bird-man used to spend his official year on the mountain in which the monoliths were quarried; the bird initiation of children was also performed in connec. tion with the statues, and the ring design on the back of the images was reproduced at the ceremony on the children's backs. There seems reason to believe, says the writer, that the people who originally celebrated the bird cult included in it reverence for the statues. The ancestors of the present inhabitants were, therefore, either the makers of the monoliths of Easter Island, or, if the bird worshippers represent a more 
recent migration, the old religion of the images was blended into, and perpetuated by, the more recent culture.

The conclusions of Mrs. Scoresby Routledge have been extended by a second paper in the same issue of Folk-lore by Mr. Henry Balfour on the ethnological affinities of the natives of Easter Island. $\mathrm{He}$ arrives at the conclusion that the island culture is composite, and exhibits traces of fusion of at least two stocks. The first was a Melanesian migration, which introduced the practice of distending the ear-lobe, a characteristic style in art, certain special types of stone implements, and the cult of the frigate-bird, which was designed as a magical method of increasing the food supply. This Melanesian culture was submerged by a wave of Polynesian immigrants, to whom is due a new bird cult, aiming at increasing in a like magical way the supply of birds and eggs. This culture seems to be closely allied to that of the Solomon Islands, and "it seems likely that the symbolism of many of the ideographic signs employed in the Easter Island script may be explained by a study on the spot of closely similar designs still used in the Solomon Islands, the symbolic significance of which might be ascertained before it is too late." Thus a survey of the materials collected by $\mathrm{Mr}$. and Mrs. Scoresby Routledge, interpreted by the wide ethnographical knowledge of Mr. Henry Balfour, seems to bring us at last within reach of a solution of the mystery of Easter Island. It may be hoped that the clues suggested by him will be followed by some careful local anthropologist.

\section{SCIENTIFIC ACTIVITIES OF THE SMITHSONIAN INSTITUTION.}

THE report of the secretary of the Smithsonian Institution for the year ending June 30 , I917, has been received from Washington. It reviews the affairs of the institution, summarises briefly the operations of its several branches, and, in addition, contains, in the form of appendices, detailed reports by the assistantsecretary and others directly in charge of its various activities.

The permanent fund of the institution now amounts to 200,00ol., the limit authorised by Congress. The income during the year under review reached $17,730 l$, and with the cash balance from the previous year the total resources for the financial year amounted to $26,672 l$. The disbursements for the same period were $24,830 l$.

The former secretary of the institution, the late Prof. S. P. Langley, demonstrated in 1896 the feasibility of mechanical flight by a machine heavier than the air propelled by its own power. As an indication of America's debt to his researches, his name is fittingly preserved in the name "Langley Field," a tract of some 1800 acres near Hampton, Va., where important experiments in aviation are now being carried on. The large machine with which Prof. Langley experimented in 1903 proved its worth and its capability of flight during the year reviewed by the report. The institution has established a research laboratory at Langley Field for scientific investigations, and among several sub-committees engaged in the study of aeronautic problems may be mentioned those on aerial mail service, aero torpedoes, aircraft communicating, airplane mapping, the relation of the atmosphere to aeronautics, and the construction and navigation of aircraft.

The usual activities of the institution were continued during the year in carrying out one of its fundamental objects, the increase of knowledge. Various explorations and researches were inaugurated or participated NO. 253 I, VOL. IOI in by the institution, covering the different divisions of astronomical, anthropological, biological, and geological science; but the secretary points out that opportunities for undertaking important lines of investigation are constantly being lost through lack of means to carry them into execution. Moreover, several proposed expeditions to various parts of the world have been delayed temporarily by the war.

The report directs attention again to the work of the Research Corporation, organised in 1912, and having as its officers men particularly interested in the development of industry. The principal income of the corporation is derived from royalties for the use of the Cottrell process for the electrical precipitation of suspended particles. Dr. F. G. Cottrell, the inventor of the process, offered his patents to the Smithsonian, Institution, but as it was impracticable for the institution to administer them commercially, the Research Corporation was organised for that purpose. The corporation seeks to do for industry what other institutions are doing for science, for medicine, and for the improvement of social conditions. An annual fellowship has been established "open to general competition for the purpose of encouraging and assisting men of science in the prosecution of their investigations." To the successful competitor the corporation offers an honorarium of $500 l$, and the assistance of the corporation in securing the most favourable opportunity for prosecuting the particular object of study.

The additions to the libraries of the institution and its branches during the year numbered more than 9000 volumes and pamphlets. Among important gifts were a first consignment of $56 \mathrm{r}$ volumes and 293 pamphlets, part of the botanical library of Dr. J. D Smith, of Baltimore, and the scientific library of Dr. E. A. Mearns, an American zoologist who died in I9I6.

With the secretary's report for I9I7 may be noticed conveniently the annual report of the Board of Regents of the Smithsonian Institution for the year ending June 30 , I916, which has now come to hand. This handsome and well-illustrated volume of 608 pages includes the secretary's report for 1916, to which we directed attention last year; but its most attractive feature is the comprehensive general appendix, with its invaluable selection of miscellaneous scientific memoirs intended for the use of correspondents of the institution, teachers, and other workers engaged in the promotion of knowledge. Among the memoirs are original contributions, translations from foreign periodicals, and reprints from scientific serial publications printed in English.

The original contributions include papers by Prof. C. G. Abbot, director of the Astrophysical Observatory of the institution, on news from the stars; Prof. Paul Bartsch, curator of marine invertebrates in the U.S. National Museum, on pirates of the deep-stories of the squid and octopus; Prof. Albert Mann, on the economic importance of the diatoms; Mr. W. E. Safford, economic botanist to the U.S. Department of Agriculture, on narcotic plants and stimulants of the ancient Americans; Dr. J. W. Fewkes, on a prehistoric Mesa Verde Pueblo and its people; and Mr. Van H. Manning, on mine safety devices developed by the United States Bureau of Mines.

The translations include an address by Prof. A. Pictet, professor of chemistry at the University of Geneva, on molecular structure and life, published in the Revue Scientifique and the author's "Extrait des Archives des Sciences physiques et naturelles, Geneva, I9I5"; a lecture delivered in German in I9I4 in Vienna by Prof. F. Berwerth, on the origin of meteorites; and a lecture given in French by Prof. M. Caullery, exchange professor at Harvard University in I9I6, on the present state of the problem of evolution. 